Nota científica

(Short communication)

\title{
DATOS PRELIMINARES SOBRE EL PAPEL DEL VENADO COLA BLANCA ODOCOILEUS VIRGINIANUS (ARTIODACTYLA: CERVIDAE) COMO DISPERSOR DE SEMILLAS
}

\author{
PRELIMINAR DATA OF WHITE TAILED-DEER ODOCOILEUS VIRGINIANUS \\ (ARTIODACTYLA: CERVIDAE) AS SEED DISPERSER
}

\author{
MIRIAM GARCÍA RUIZ ${ }^{1}$, ELLEN ANDRESEN ${ }^{2}$, GUADALUPE XOCHITL MALDA BARRERA ${ }^{1 *}$, SERGIO \\ GUERRERO VÁZQUEZ ${ }^{3}$, ISRAEl GUSTAVo CARRILLO ANGELES ${ }^{1}$, MóNICa ELISA QUEIJEIRO \\ BOLAÑOS
}

\footnotetext{
${ }^{1}$ Laboratorio de Ecología, Facultad de Ciencias Naturales, Universidad Autónoma de Querétaro, Cerro de las Campanas s/n, Las Campanas, 76010 Santiago de Querétaro, Querétaro.<garciamruiz@gmail.com>; <gmalda@uaq.mx>; <israel.carrillo@uaq.mx>; $<$ monicq15@yahoo.com>

${ }^{2}$ Instituto de Investigaciones en Ecosistemas y Sustentabilidad, Universidad Nacional Autónoma de México, Antigua Carretera a Pátzcuaro 8701, Col. Ex Hacienda de San José de la Huerta, 58190 Morelia, Michoacán. <andresen@ cieco.unam.mx>

${ }^{3}$ Laboratorio de Zoología, Centro Universitario de Ciencias Biológicas y Agropecuarias, Universidad de Guadalajara, Camino Ramón Padilla Sánchez 2100, Nextipac, 44600 Zapopan, Jalisco. <sergioguerrerovazquez@ gmail.com>

*Autor de correspondencia: <gmalda@uaq.mx>
}

Recibido: 17/11/2017; aceptado: 06/11/2018; publicado en línea: 29/03/2019

Editor responsable: Magdalena Cruz Rosales

García-Ruiz, M., Andresen, E., Malda-Barrera, G. X., Guerrero-Vázquez, S., Carrillo-Angeles, I. G., Queijeiro-Bolaños, M. E. (2019) Datos preliminares sobre el papel del venado cola blanca Odocoileus virginianus (Artiodactyla: Cervidae) como dispersor de semillas. Acta Zoológica Mexicana (nueva serie), 35, 1-6. https://doi.org/10.21829/azm.2019.3502200

RESUMEN. El papel del venado cola blanca como dispersor endozoócoro de semillas se evaluó a través de la estimación del número de semillas y especies encontradas en las muestras fecales, y el análisis del efecto del paso por el tracto digestivo sobre el porcentaje y la velocidad de germinación en semillas de una especie focal (Acacia schaffneri). En total se encontraron 369 semillas en 98 grupos de pellets. La mayoría de las semillas se apreciaban dañadas o inmaduras, sólo 67 semillas (31 morfoespecies) germinaron. El porcentaje de germinación de semillas de A. schaffneri defecadas tendió a ser mayor que la germinación de semillas control. En nuestro estudio el venado figura como depredador de semillas y ocasionalmente como dispersor de semillas. Sin embargo, nuestros resultados con animales en cautiverio muestran que el venado puede incrementar el porcentaje de germinación de algunas especies.

Palabras clave: Venado cola blanca; bosque La Primavera; dispersión endozoócora

García-Ruiz, M., Andresen, E., Malda-Barrera, G. X., Guerrero-Vázquez, S., Carrillo-Angeles, I. G., Queijeiro-Bolaños, M. E. (2019) Preliminar data of white tailed-deer Odocoileus virginianus (Artiodactyla: Cervidae) as seed disperser. Acta Zoológica Mexicana (nueva serie), 35, 1-6. https://doi.org/10.21829/azm.2019.3502200 


\begin{abstract}
The role of white-tailed deer in endozoochorus seed dispersal was evaluated by estimating the number of seeds and seed species found in fecal samples and assessing the effect of gut passage on germination percentage and speed for a focal seed species (Acacia schaffneri). A total of 369 seeds were found in 98 pellet groups. Most seeds appeared to be damaged or immature, and only 67 seeds (31 morphospecies) germinated. Germination percentage of defecated seeds of $A$. schaffneri tended to be higher than germination of control seeds. In our study site white-tailed deer appears to be acting mainly as a seed predator for ingested seeds, and occasionally as a seed disperser. Nevertheless, our results using captive animals suggest that white-tailed deer may improve seed germination of particular plant species.
\end{abstract}

Key words: White-tailed deer; La Primavera Forest; endozoochorous seed dispersal

El venado cola blanca, Odocoileus virginianus (Zimmermann, 1780), es un herbívoro generalista y principalmente ramoneador que también se ha reportado como dispersor de semillas (Myers et al., 2004; Williams et al., 2008). Su potencial importancia como dispersor radica en que, al ser un mamífero grande, con alta movilidad y generalista, puede transportar las semillas a grandes distancias (Vellend et al., 2003). A pesar de esto, resulta difícil generalizar su función como dispersor, ya que puede tener diferentes efectos sobre la germinación de las semillas que consume (Jara-Guerrero et al., 2018). Por lo anterior y debido a que en México existe poca información sobre esta especie en su función como dispersora de semillas, se realizó la presente investigación con los objetivos de: (i) determinar las especies de semillas contenidas en excretas de este ungulado en un Área Natural Protegida (ANP) de Jalisco y (ii) evaluar el efecto del paso por el tracto digestivo del venado sobre la germinación de semillas de una especie característica de zonas áridas y semiáridas de México, Acacia schaffneri (S. Watson) F.J. Herm.

Para el primer objetivo, se colectaron 98 grupos de pellets enteros de venado cola blanca en un bosque de encino-pino y vegetación secundaria dentro del Área de Protección de Flora y Fauna La Primavera (BLP; en Jalisco, México; 635040 m E; 2295019 m N y 661815 m E; 273893 m N), entre marzo y octubre del año 2015. Los pellets se limpiaron y se desinfectaron con una solución fungicida; se desbarataron y revisaron con un estereoscopio para separar, cuantificar e identificar las semillas. Las semillas y los pellets desbaratados se almacenaron a una temperatura promedio de $4^{\circ} \mathrm{C}$ durante un mes, siguiendo la metodología propuesta por Myers et al. (2004). Posteriormente, las semillas se colocaron en cajas Petri con papel filtro húmedo y los pellets desbaratados se colocaron en charolas sobre una cama de vermiculita. Las cajas y charolas se mantuvieron en una cámara de crecimiento con control de luz (16 horas luz/8 horas oscuridad) y temperatura promedio de $22.7 \pm 2.4^{\circ} \mathrm{C}$. La germinación se registró cuando se evidenció la emergencia de la radícula, durante dos meses. Las plántulas fueron identificadas hasta el nivel taxonómico más fino posible.

Para el segundo objetivo se trabajó en el Parque Nacional El Cimatario (PNEC, Querétaro, México). Se colectaron 88 grupos de pellets (entre noviembre y diciembre 2015) en un corral de 2 ha en el que se mantienen ejemplares de $O$. virginianus y en donde hay una alta densidad de árboles de Acacia schaffneri, cuyas vainas son consumidas por los venados (MGR, obs. pers.). Los grupos de pellets se usaron en dos experimentos de germinación: (A) germinación de semillas de A. schaffneri presentes dentro de pellets intactos (33 grupos de pellets) y (B) germinación de semillas extraídas de los pellets ( 160 semillas obtenidas de 55 grupos de pellets). En ambos experimentos se cuantificó el porcentaje y velocidad de germinación y se usaron semillas extraídas de vainas como control.

Para el experimento (A), los pellets intactos y semillas control $(n=101$ semillas $)$ fueron colocados en charolas de plástico sobre una cama de vermiculita dentro de un invernadero con una temperatura promedio de $17.1 \pm 8.9^{\circ} \mathrm{C}$. Los pellets y semillas se mantuvieron húmedos y durante dos meses se registró la germinación. Para el experimento (B), las 160 semillas extraídas de los pellets y otras 160 semillas control, fueron sumergidas durante dos minutos en hipoclorito de sodio al $2 \%$ y posteriormente colocadas en cajas 
Petri (cuatro cajas por tratamiento, cada una con 40 semillas) dentro de una cámara de crecimiento con control de luz (16 horas luz /8 horas oscuridad) y temperatura $\left(25^{\circ} \mathrm{C}\right)$. La germinación se revisó durante 65 días. Con las semillas de A. schaffneri que no germinaron, se realizó una prueba indirecta de viabilidad con cloruro de tetrazolio, considerando tres categorías de tinción: nula o suave para semillas no viables, media e intensa (50-75\% y >75\% del embrión teñido, respectivamente) para semillas viables.

De los pellets colectados en BLP, se identificaron 31 morfoespecies distintas de semillas. Nueve de las morfoespecies fueron identificadas al menos a nivel de familia; ocho especies se lograron identificar hasta género, de las cuales cinco fueron herbáceas y tres leñosas, siendo los géneros más representados Vaccinium (35 semillas), Acacia (17 semillas) y Solanum (13 semillas; Cuadro 1). El 29\% de los grupos fecales colectados tuvo semillas que fueron contabilizadas mediante registro directo (369 semillas) o indirecto a partir de las plántulas que emergieron de los pellets desbaratados (50 semillas). De las semillas detectadas directamente sólo 17 germinaron, registrándose 15 morfoespecies. De las semillas restantes, 296 presentaron daño físico, estaban parasitadas o inmaduras. En el registro indirecto, 50 plántulas que emergieron de los pellets desbaratados se clasificaron en 18 morfoespecies.

Cuadro 1. Semillas defecadas por venados cola blanca en el bosque La Primavera que lograron identificarse por lo menos a nivel de familia.

\begin{tabular}{cccccc}
\hline Familia & Género & Especie & $\begin{array}{c}\text { Forma de } \\
\text { vida }\end{array}$ & $\begin{array}{c}\text { Ancho y largo } \\
\text { de las semillas } \\
\text { (mm) }\end{array}$ & $\begin{array}{c}\text { Número de } \\
\text { semillas } \\
\text { (germinaciones) }\end{array}$ \\
\hline Ericaceae & Vaccinium & stenophyllum & arbusto & $2 \times 1$ & $35(11)$ \\
Fabaceae & Acacia & pennatula & árbol/arbusto & $7 \times 6$ & $17(4)$ \\
Lamiaceae & - & - & - & - & $1(1)$ \\
Myrtaceae & Psidium & guajava & árbol & $3 \times 3$ & $8(5)$ \\
Oxalidaceae & Oxalis & - & herbácea & $1 \times 1$ & $2(0)$ \\
Phytolaccaceae & Phytolacca & icosandra & herbácea & $3 \times 3$ & $4(1)$ \\
Poaceae & Paspalum & - & herbácea & $2 \times 1$ & $1(0)$ \\
Solanaceae & Physalis & - & herbácea & $3 \times 3$ & $5(3)$ \\
Solanaceae & Solanum & - & herbácea & $2 \times 2$ & $13(0)$ \\
\hline
\end{tabular}

En ambos experimentos, el porcentaje de germinación de semillas que provenían de excretas de los venados en cautiverio fue mayor que de semillas control $(p<0.05$; Cuadro 2). No se detectó diferencia en la velocidad de germinación entre las semillas obtenidas de las excretas y las semillas control $(0.120$ semillas/día vs. 0.126 semillas/día; $\mathrm{t}=2.447$; g.l. $=6 ; p=0.905)$. La mayoría de las semillas que no germinaron mostraron baja probabilidad de viabilidad (tinción suave), sin diferencia entre las semillas de pellets y las semillas control ( $50 \%$ y $47 \%$, respectivamente; $\chi^{2}=0.211$; g.l. $\left.=2 ; p<0.899\right)$.

Son diversos los factores que determinan la calidad (sensu Schupp et al., 2010) de un animal como dispersor de semillas. Estos factores están relacionados con la manipulación y el tratamiento de las semillas, y con los patrones de deposición de las mismas (Mandujano et al., 1994; Andresen, 2012). Se sabe, por ejemplo, que en términos de manipulación, los ungulados pueden defecar, escupir, masticar o digerir las semillas, dependiendo en gran medida del tamaño de las mismas y de la especie animal (Bodmer et al., 1991). En general, nuestros resultados sugieren que en BLP el venado cola blanca actúa como un dispersor de semillas de baja calidad, debido a que la gran mayoría (80\%) de semillas encontradas en los pellets estaban dañadas o eran inmaduras, lo que representa un efecto negativo en la reproducción de las plantas (Ford et al., 2003). El bajo porcentaje de germinación de semillas obtenidas a partir de excretas en este estudio, contrasta con otros trabajos que demuestran un mayor porcentaje de germinación y más especies dispersadas por el venado cola blanca (Myers et al., 2004; Williams et al., 2008). Esto podría deberse, en 
parte, a diferencias en la metodología usada para las pruebas de germinación, lo cual es reconocido como un factor causal de la variación en este tipo de estudios (Traveset et al., 2007).

Encontramos, sin embargo, que el paso por el tracto digestivo del venado tuvo efecto positivo en la germinación de una especie focal, Acacia schaffneri. El efecto del paso por el tracto digestivo de los animales puede variar mucho, y depende tanto de la especie animal como de la especie de planta (Traveset 1998). Así, por ejemplo, en México, un estudio reportó que el venado cola blanca dispersó por regurgitación gran cantidad de semillas viables de Spondias purpurea (Mandujano et al., 1994). En otros estudios con venado cola blanca se ha visto que puede no haber efecto sobre la germinación (e.g. Trillium stoloniferum, Ford et al., 2003), o que puede haber un efecto negativo (e.g. Caesalpinia glabrata, Jara-Guerrero et al., 2018). Sin embargo, también debe considerarse la digestión total de las semillas en el tracto digestivo. Por ejemplo, en el estudio con T. stoloniferum, de las 300 semillas consumidas sólo se recuperaron 80, por lo que se puede decir que los venados tuvieron un efecto negativo al destruir las semillas mediante su digestión (Ford et al., 2003). En el caso de las semillas de A. schaeffneri ingeridas por el venado, su germinación pudo haber sido favorecida por la escarificación mecánica y/o química de la testa, la cual es muy dura e impermeable. Diversas especies de leguminosas se caracterizan por tener dormancia física y requerir algún tipo de escarificación para germinar (Argel \& Paton, 1999). Por ejemplo, la germinación de semillas de Heteroflorum sclerocarpum en un bosque tropical caducifolio de México se vio favorecida mediante la escarificación mecánica ocurrida durante la manipulación bucal por venados cola blanca (Urrea-Galeano et al., 2018). Por otro lado, el excremento que rodea a las semillas defecadas puede tener efectos positivos o negativos sobre su supervivencia, germinación y el establecimiento de plántulas (Andresen, 2012). Por ejemplo, la materia fecal puede actuar como un sustrato favorable para las plántulas que logran emerger de las semillas (Traveset, 1998); pero también pueden aumentar la infección por patógenos o inhibir la germinación (Traveset et al., 2007). Nuestros resultados con los pellets colectados en BLP sugieren que la germinación de ciertas especies de semillas se vio favorecida por la disgregación de los pellets, como ha sido reportado anteriormente (Blyth et al., 2013). Sin embargo, en los experimentos de germinación con $A$. schaffneri, el máximo porcentaje de germinación (25\%) fue observado en semillas dentro de pellets intactos (Cuadro 2).

Cuadro 2. Semillas totales y semillas germinadas en los experimentos: germinación de semillas de Acacia schaffneri presentes dentro de pellets intactos (A) y germinación de semillas extraídas de los pellets (B). El tamaño de las semillas es de $7 \mathrm{~mm} \times 6 \mathrm{~mm}$.

\begin{tabular}{cccc}
\hline Experimento & \# Semillas totales & $\begin{array}{c}\text { \# Semillas } \\
\text { germinadas } \\
\text { (porcentaje) }\end{array}$ & Análisis estadístico \\
\hline Excretas (A) & 71 & $18(25 \%)$ & $\chi^{2}=15.240$, g.l. $=1, p<0.0001$ \\
Control (A) & 101 & $4(4 \%)$ & \\
Excretas (B) & 160 & $27(17 \%)$ & $\chi^{2}=4.028$, g.l. $=1, p=0.0447$ \\
Control (B) & 160 & $14(9 \%)$ & \\
\hline
\end{tabular}

Finalmente, la distancia con respecto a la planta progenitora es un factor que influye la calidad de un dispersor, debido a que frecuentemente la mortalidad de las semillas o plántulas es mayor cerca de la planta madre (Andresen, 2012). En este sentido, se considera que los mamíferos herbívoros grandes son importantes para la dispersión de semillas a larga distancia (> $1 \mathrm{~km}$; Vellend et al., 2003). Sin embargo, en el presente estudio se observaron semillas de Vaccinium stenophyllum y Psidium guajava únicamente en pellets recolectados en los sitios en los que estas especies estaban presentes (MG-R, obs. pers.). Aunque esto sugiere una dispersión de semillas espacialmente restringida, son necesarios otros estudios para determinar las distancias de dispersión por el venado cola blanca. 
En el presente estudio, se pudo observar que, aunque el venado cola blanca dispersa semillas viables de varias especies e incluso puede favorecer un aumento en el porcentaje de germinación de algunas, actúa de manera primaria como un depredador de semillas y por lo tanto un dispersor de baja calidad. Sin embargo, es importante considerar que las interacciones entre especies son muy complejas. En el caso de la dispersión de semillas por animales, los resultados de las interacciones son contexto-y/o especie-dependientes (Andresen, 2012), por lo que son necesarios estudios a largo plazo para poder determinar la función que juega el venado cola blanca como dispersor de semillas en los ecosistemas de México.

AgradeCimiEnTOS. Agradecemos al Consejo Nacional de Ciencia y Tecnología por el otorgamiento de la Beca CONACYT Nacional (2014-2016). Asimismo, reconocemos el apoyo y los permisos concedidos por El Organismo Público Descentralizado Bosque La Primavera y el personal del Parque Nacional El Cimatario. Finalmente, queremos agradecer el apoyo especial brindado por el Biol. Gerardo Cabrera para la logística de las colectas.

\section{LITERATURA CITADA}

Andresen, E. (2012) Dispersión de semillas por animales frugívoros y granívoros. Pp. 101-139. In: E. Del Val, Boege, K. (Coords). Ecología y evolución de las interacciones bióticas. Fondo de Cultura Económica, México.

Argel, P. J., Paton, C. J. (1999) Overcoming legume hardseedness. Pp. 247-265. In: Loch, D. S., Ferguson, J. E. (Eds.). Forage seed production: tropical and sub-tropical species. CABI, United Kingdom.

Blyth, L. H., Ouborg, L. J., Johnson, D. M., Anderson, L. J. (2013) The short-term germination and establishment success of deer-dispersed seeds in mesic temperate forests. The Journal of the Torrey Botanical Society, 140, 334-348.

Bodmer, R. E. (1991) Strategies of seed dispersal and seed predation in Amazonian ungulates. Biotropica, 23, 255-261.

Ford, W. M., Madarish, D., Schuler, T. M., Castleberry, S. B. (2003) Influence of white-tailed deer digestion on running buffalo clover (Trifolium stoloniferum: Fabaceae Muhl. ex A. Eaton) Germination. American Midland Naturalist, 149, 425-428.

Jara-Guerrero, A., Escribano-Avila, G., Espinosa, C. I., De la Cruz, M., Méndez, M. (2018) Whitetailed deer as the last megafauna dispersing seeds in Neotropical dry forests: the role of fruit and seed traits. Biotropica, 50, 169-177.

Mandujano, S., Gallina, S., Bullock, S. H. (1994) Frugivory and dispersal of Spondias purpurea (Anacardiaceae) in a tropical dry forest of Mexico. Revista de Biología Tropical, 42, 105-112.

Myers, J. A., Vellend, M., Gardescu S., Marks, P. L. (2004) Seed dispersal by white-tailed deer: implications for long-distance dispersal, invasion, and migration of plants in eastern North America. Oecologia, 139, 35-44.

Schupp, E. W., Jordano, P., Gómez, J. M. (2010) Seed dispersal effectiveness revisited: a conceptual review. New Phytologist, 188, 333-353.

Traveset, A. (1998) Effect of seed passage through vertebrate frugivores' guts on germination: a review. Perspectives in Plant Ecology. Evolution and Systematics, 1, 151-190.

Traveset, A., Robertson, A. W., Rodríguez-Pérez, J. (2007) A review on the role of endozoochory in seed germination. Pp. 78-103. In: Dennis, A. J., Schupp, E. W., Green, R. J., Westcott, D. A. (Eds.). Seed dispersal. Theory and its application in a changing world. CABI Publishing, Oxon, UK.

Urrea-Galeano, L. A., Andresen, E., Ibarra-Manríquez, G. (2018) Importancia de las interacciones semilla-mamífero para Heteroflorum (Leguminosae), un género monoespecífico endémico de México. Revista Mexicana de Biodiversidad, 89, 497-506.

Vellend, M., Myers, J. A., Gardescu, S., Marks, P. L. (2003) Dispersal of Trillium seeds by deer: implications for long distance migration of forest herbs. Ecology, 84, 1067-1072. 
García-Ruíz et al.: Datos preliminares del venado como dispersor

Williams, S. C., Ward, J. S., Ramakrishnan, U. (2008) Endozoochory by white-tailed deer (Odocoileus virginianus) across a suburban/woodland interface. Forest Ecology and Management, 255, 940947. 